\title{
Balloon angioplasty of adult aortic coarctation
}

\author{
K Phadke, J F Dyet, C P Aber, W Hartley
}

\begin{abstract}
Objective-To examine the use of balloon angioplasty in the treatment of native adult aortic coarctation.

Design-Haemodynamic and angiographic studies to establish the diagnosis of aortic coarctation were established before carrying out the procedure in all patients.

Setting-All the studies and angiographic procedures were performed in a large district general hospital within the departments of cardiology and radiology. There was careful perioperative monitoring. The mean hospital stay was three days.

Patients-15 adult patients (with clinical, haemodynamic, and angiographic evidence of native aortic coarctation) were considered for this treatment. 13 were offered balloon angioplasty. One was excluded, as there was no significant gradient across the lesion. One patient had complete atresia at the site of the coarctation.
\end{abstract}

Interventions-Percutaneous transluminal balloon angioplasty was carried out with balloon catheters diameter $2 \mathrm{~mm}$ less than the diameter of the aorta immediately below the left subclavian artery to minimise the possibility of tearing the aortic wall.

Main outcome measures-Abolition or significant reduction of the preoperative gradient was achieved in all 13 patients treated. Reduction in blood pressure of the upper limb was also achieved in all of the patients. Only four patients required continued antihypertensive treatment. Two patients developed false aneurysms after the procedure and required surgery. No deaths occurred. These results compare favourably with conventional surgery and are much more economical.

Conclusions-Balloon angioplasty could become the first line treatment for all patients with native adult aortic coarctation, but longer term follow up is required to validate this.

Cardiac and Radiology Departments, Hull Roya Infirmary, Kingston

Upon Hul

K Phadke

J F Dyet

C P Aber

W Hartley

Correspondence to:

Dr J F Dyet, Cardiovascular Radiology Department, Hull

Royal Infirmary, Anlaby Road

Kingston Upon Hull HU3 2JZ.

Accepted for publication

26 May 1992.
(Br Heart J 1993;69:36-40)

Balloon angioplasty for aortic coarctation was first described in 1982, and by 1989 over two hundred cases had been documented in world publications. Most were infants and young children. Although initial results were encouraging with abolition of the coarctation gradient and relief of systemic hypertension, the long-term results have been less impressive. Where the angioplasty was performed during infancy a high restenosis rate (up to $40 \%$ ) has been reported. ${ }^{1}$ A survey of published work suggests that the older the child a angioplasty the less is the likelihood of restenosis, and in one adult series of eight cases, the results at one year follow up were good $(0 \%$ restenosis). ${ }^{2}$

We describe our experience with 15 adults This is the first series reported by a British centre.

Patients and methods

Between March 1987 and March 1991 angiography with a view to angioplasty was performed on 15 patients (10 men and five women) with native aortic coarctation. The age range was 16 to 60 (mean 35.53) years. The first five patients underwent diagnostic catheterisation with angioplasty as a separate procedure, whereas we offered our last 10 patients angiography and angioplasty as a combined procedure.

Eleven $(73 \%)$ of the 15 patients presented with hypertension, one $(6 \cdot 6 \%)$ with breathlessness, one $(6.6 \%)$ with a possible hypoplastic

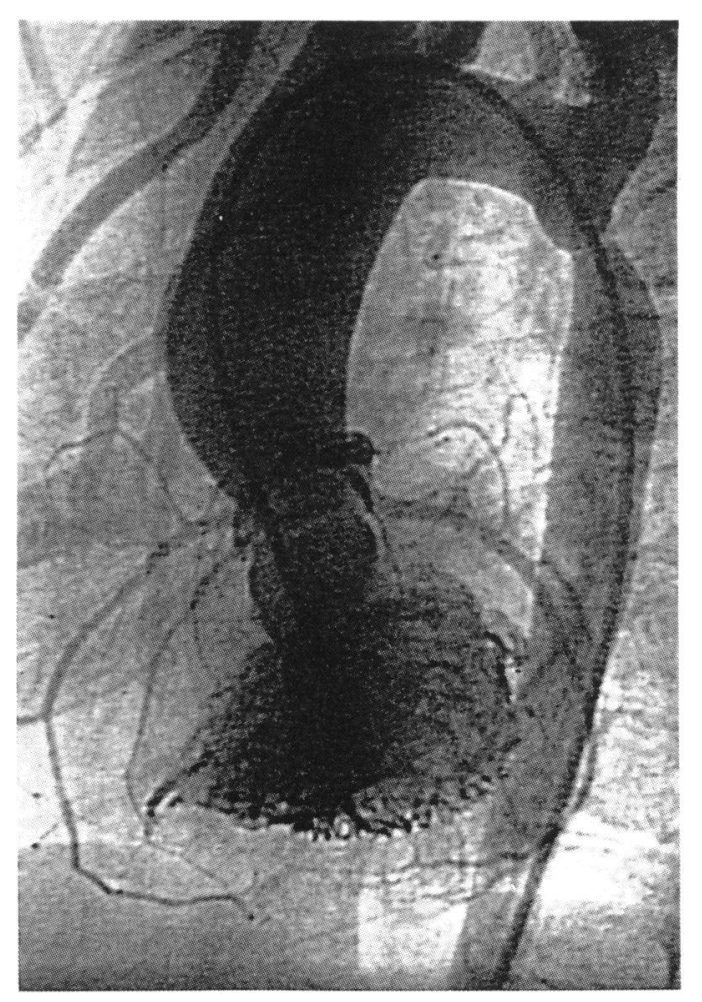

Figure 1 Angiogram of the aortic arch before dilatation showing the site of the coarctation-left anterior oblique projection. 
Figure 2 Angioplasty balloon partially inflated.

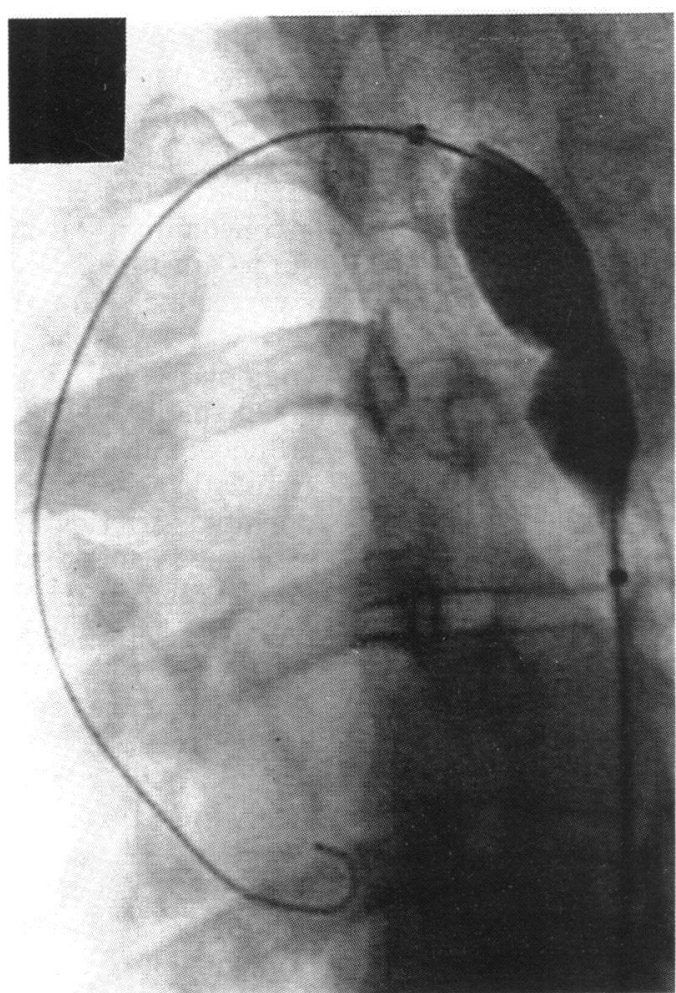

left heart syndrome, and two (13.3\%) were found to have coarctation at a routine employment medical examination.

All 15 patients were hypertensive and had typical clinical signs of coarctation. Eight $(53 \%)$ patients had rib notching on the chest radiograph. Electrocardiographic evidence of left ventricular hypertrophy was present in nine $(60 \%)$ patients.

\section{Method}

Informed consent was obtained before the procedure. Aspirin (300 mg daily) and dipyridamole ( $100 \mathrm{mg}$ thrice daily) were given 48 hours before the procedure and continued for three months. This regime was given on an empirical basis and we are not sure if anteplatelet drugs are really required in this situation.

In our experience, angioplasty of the abdominal aorta can cause considerable pain and because of this we elected to use general anaesthesia. The right femoral artery was punctured with the Seldinger technique. If the artery was impalpable Doppler ultrasound was used to locate it. A 0.038 inch straight $145 \mathrm{~cm}$ guide wire was put into the abdominal aorta and then a 7 French Judkins right coronary catheter was passed over the wire. The abdominal aortic pressures were measured. The right coronary catheter and guide wire combination were used to explore the coarctation until the lumen was found. The guide wire and catheter were then put into the ascending aorta, and the proximal aortic pressure was measured. By means of a $250 \mathrm{~cm} \mathrm{~J}$ exchange wire the coronary catheter was exchanged for a $7 \mathrm{~F}$ pigtail catheter. An aortic arch angiogram was performed in the left anterior oblique position, injecting $60 \mathrm{ml}$ of Iopamidol 370 at $30 \mathrm{ml} / \mathrm{s}$ (fig
1). The images were recorded on grey scale digital imaging (Philips Medical Systems DCI) at 12.5 frames/s. The aortic diameter immediately distal to the origin of the left subclavian artery, proximal to the coarctation was measured with the inbuilt computer programme.

The $250 \mathrm{~cm} \mathrm{~J}$ exchange wire was left across the coarctation, the pigtail catheter was withdrawn, and a sheath (10-14 F gauge) was inserted ino the femoral artery. A bolus of 5000 units of heparin was given through the side arm of the sheath.

The size of the balloon was chosen to be 2 $\mathrm{mm}$ less than the aortic diameter immediately below the left subclavian artery. The balloon was primed with dilute contrast by hand. The $10 \mathrm{~F}$ balloon catheter was then advanced up the aorta until it lay across the coarctation.

Partial inflation of the balloon allowed us to identify the level of the waist of the coarctation to ensure the balloon was satisfactorily positioned (fig 2). Full inflation was then carried out until the waist in the ballon disappeared (fig 3 ). This required a pressure between 2 and 4 atmospheres. The balloon remained inflated for $60 \mathrm{~s}$. After deflation, simultaneous pressures were recorded from the tip of the balloon catheter and the side arm of the sheath. If a gradient remained, a further inflation to a slightly higher pressure was performed. After abolition of the gradient the balloon catheter was withdrawn over the exchange wire with the balloon under negative pressure. The $7 \mathrm{~F}$ pigtail catheter was advanced into the aortic arch and a further angiogram performed (fig 4). Finally, a withdrawal gradient was taken across the coarctation site through the pigtail catheter.

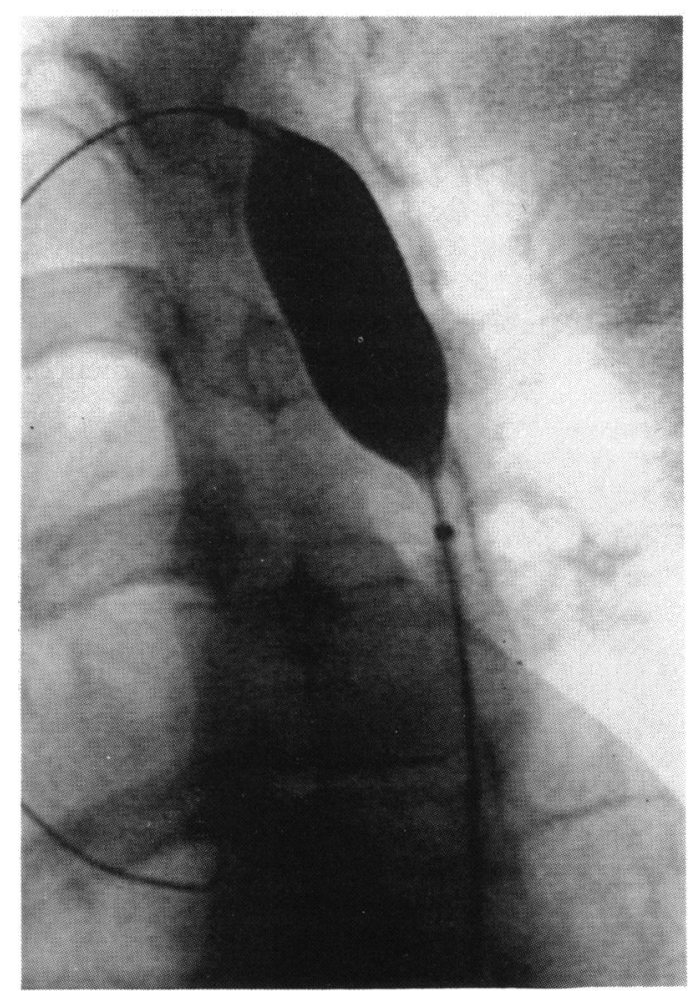

Figure 3 Angioplasty balloon fully inflated. 
Figure 4 Angiogram of the aortic arch after dilatation-left anterior oblique projection.

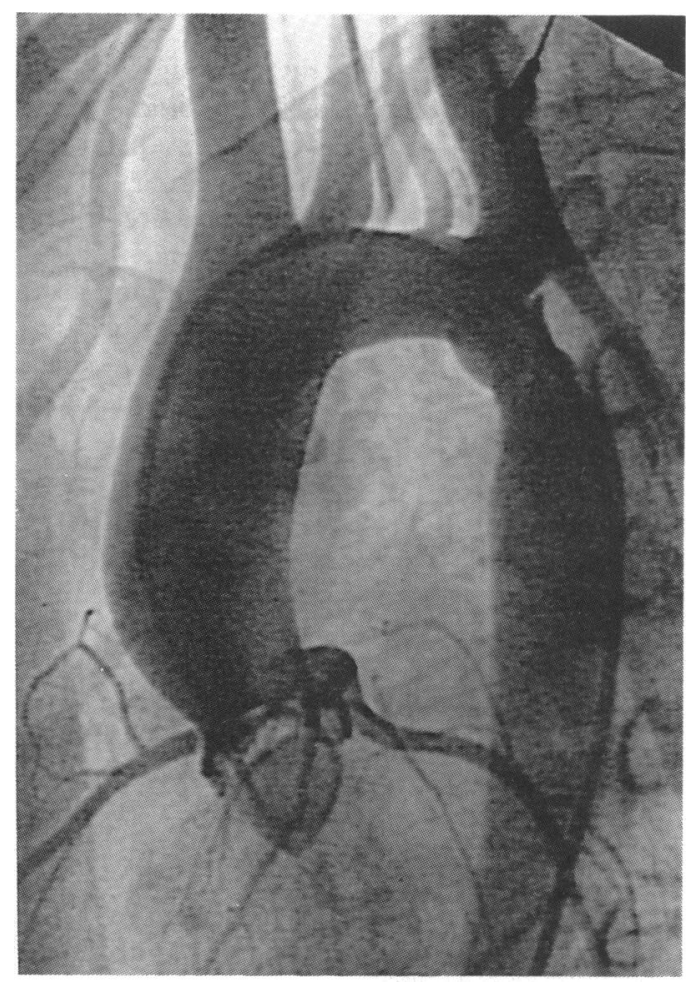

One patient JS (table) had a hypoplastic segment immediately below the left subclavian artery which measured only $11.5 \mathrm{~mm}$. This was dilated serially with an $8 \mathrm{~mm}$ then a $10 \mathrm{~mm}$ balloon. No attempt was made to achieve any further dilatation at this stage despite a residual gradient of $35 \mathrm{~mm} \mathrm{Hg}$ as the femoral pulses because palpable and the postoperative angiogram showed disappearance of the intercostal collaterals.

The general anaesthetic was reversed and after the patient had been extubated the arterial sheath was removed. Haemostasis was obtained by hand pressure for 25 to 55 (mean 34) min. A pressure dressing was applied and the patient returned to the ward to lie flat for 24 hours. The patients were discharged home at 48 hours.

\section{Results}

Balloon dilatation of the coarctation was carried out in 13 of the 15 patients studied. In two patients, one with a complete atresia and one with a gradient of only $20 \mathrm{~mm} \mathrm{Hg}$ with mild hypertension and no collaterals, dilatation was not attempted.

The table lists the relevant data on patients before and after angioplasty. In all the patients who underwent angioplasty there was an immediate reduction in coarctation gradient with $\sigma$ a concomitant fall in upper limb blood pressure. Only four patients required antihypertensive treatment after the procedure. In each case this was less than had been needed before angioplasty.

One patient who had apparently undergone an uncomplicated procedure had an apparent traumatic aneurysm on the immediately postoperative arteriogram (fig 5). There was no $\mathbb{D}$ associated pain or haemodynamic disturbance. He was referred for surgery the next day when a $2 \mathrm{~cm}$ tear was found on the medial wall of the aorta. This was repaired by aortic transection $\vec{\omega}$ and end to end anastomosis. The patient had an uneventful recovery. One patient started bleeding in the recovery room from the femoral 8 artery puncture site. This was readily controlled with hand pressure. Neither paradoxical hypertension nor abdominal pain, as a $ᄋ$ consequence of engorgement of the bowel, $\rightarrow$ occurred.

All patients were reviewed clinically and nine have now been recatheterised at 12 months. Only one patient (KR) displayed a residual gradient but this was considered acceptable at $15 \mathrm{~mm} \mathrm{Hg}$, particularly as her blood pressure was normal without treatment. There was no evidence of restenosis in any of the patients.

One patient (PW) had developed a definite false aneurysm at 12 months (fig 6). This was repaired surgically with excision and Dacron patching. One other patient (AJ) had an area of pocketing above a small band seen on the right arterior oblique view (fig 7 ). This did not bulge beyond the line of the aortic wall and was not thought to be an aneurysm but to be due to incomplete disruption of the fibrous coarctation band. This patient is being reviewed regularly.

\section{Discussion}

Acceptance of any new therapeutic procedure $\frac{T}{0}$ depends on whether it is equal to or better than the traditional form of treatment. The results of of angioplasty must therefore be compared

Table Demographic data before and after operation

\begin{tabular}{|c|c|c|c|c|c|c|c|c|}
\hline Patient & $\begin{array}{l}\text { Age } \\
(y)\end{array}$ & Sex & $\begin{array}{l}\text { Gradient } \\
\text { before } \\
\text { ( } \mathrm{mm} \mathrm{Hg})\end{array}$ & $\begin{array}{l}\text { Gradient } \\
\text { after } \\
(\mathrm{mm} \mathrm{Hg})\end{array}$ & $\begin{array}{l}\text { BP before } \\
\text { (mm Hg } \\
\text { right arm) }\end{array}$ & $\begin{array}{l}B P \text { after } \\
\text { (mm } \mathrm{Hg} \\
\text { right arm) }\end{array}$ & $\begin{array}{l}F U \\
\text { (months) }\end{array}$ & Treatment after angioplasty \\
\hline $\begin{array}{l}\text { AA } \\
\text { PW } \\
\text { DS } \\
\text { KR } \\
\text { PH } \\
\text { LS } \\
\text { AJ } \\
\text { JD } \\
\text { AC } \\
\text { AD } \\
\text { NJ } \\
\text { DR } \\
\text { AH } \\
\text { BB } \\
\text { JS }\end{array}$ & $\begin{array}{l}25 \\
41 \\
26 \\
22 \\
32 \\
21 \\
16 \\
55 \\
19 \\
20 \\
26 \\
29 \\
53 \\
61 \\
27\end{array}$ & $\begin{array}{l}\mathrm{F} \\
\mathrm{M} \\
\mathrm{M} \\
\mathrm{F} \\
\mathrm{M} \\
\mathrm{M} \\
\mathrm{F} \\
\mathrm{M} \\
\mathrm{M} \\
\mathrm{F} \\
\mathrm{M} \\
\mathrm{M} \\
\mathrm{M} \\
\mathrm{M} \\
\mathrm{F}\end{array}$ & $\begin{array}{r}150 \\
80 \\
80 \\
80 \\
60 \\
70 \\
40 \\
50 \\
80 \\
20 \\
15 \\
70 \\
80 \\
60 \\
60\end{array}$ & $\begin{array}{r}15 \\
5 \\
0 \\
10 \\
5 \\
10 \\
0 \\
0 \\
0 \\
10 \\
0 \\
20 \\
35\end{array}$ & $\begin{array}{l}200 / 90 \\
170 / 100 \\
185 / 100 \\
170 / 100 \\
170 / 95 \\
150 / 80 \\
180 / 105 \\
180 / 100 \\
160 / 80 \\
150 / 110 \\
145 / 90 \\
190 / 110 \\
180 / 100 \\
250 / 90 \\
155 / 95\end{array}$ & $\begin{array}{l}120 / 80 \\
140 / 90 \\
150 / 100 \\
140 / 70 \\
140 / 80 \\
135 / 65 \\
140 / 70 \\
140 / 85 \\
120 / 75 \\
150 / 105 \\
\frac{160}{16} \\
180 / 80 \\
136 / 70\end{array}$ & $\begin{array}{r}48 \\
26 \\
30 \\
28 \\
22 \\
20 \\
18 \\
18 \\
18 \\
6 \\
3 \\
4 \\
\end{array}$ & $\begin{array}{l}\text { Nil } \\
\text { Atenolol } 50 \mathrm{mg} \text { daily } \\
\text { Nifedipine } 20 \mathrm{mg} \text { twice daily } \\
\text { Nil } \\
\text { Atenolol } 100 \mathrm{mg} \text { daily } \\
\text { Nil } \\
\text { Nil } \\
\text { Nil } \\
\text { Nil } \\
\text { Nil } \\
\text { Nil-not dilatated } \\
\text { False aneurysm resected } \\
\text { Total atresia not dilatated } \\
\text { Atenolol } 100 \mathrm{mg} \text { daily } \\
\text { Nil }\end{array}$ \\
\hline
\end{tabular}

BP, blood pressure; FU, follow up; F, female; $M$, male. 
Figure 5 Subtracted angiogram of the aortic arch showing traumatic aneurysm.

Figure 6 Angiogram of the aortic arch showing false aneurysm formation posteriorly at 12 month follow up-right anterior oblique projection.
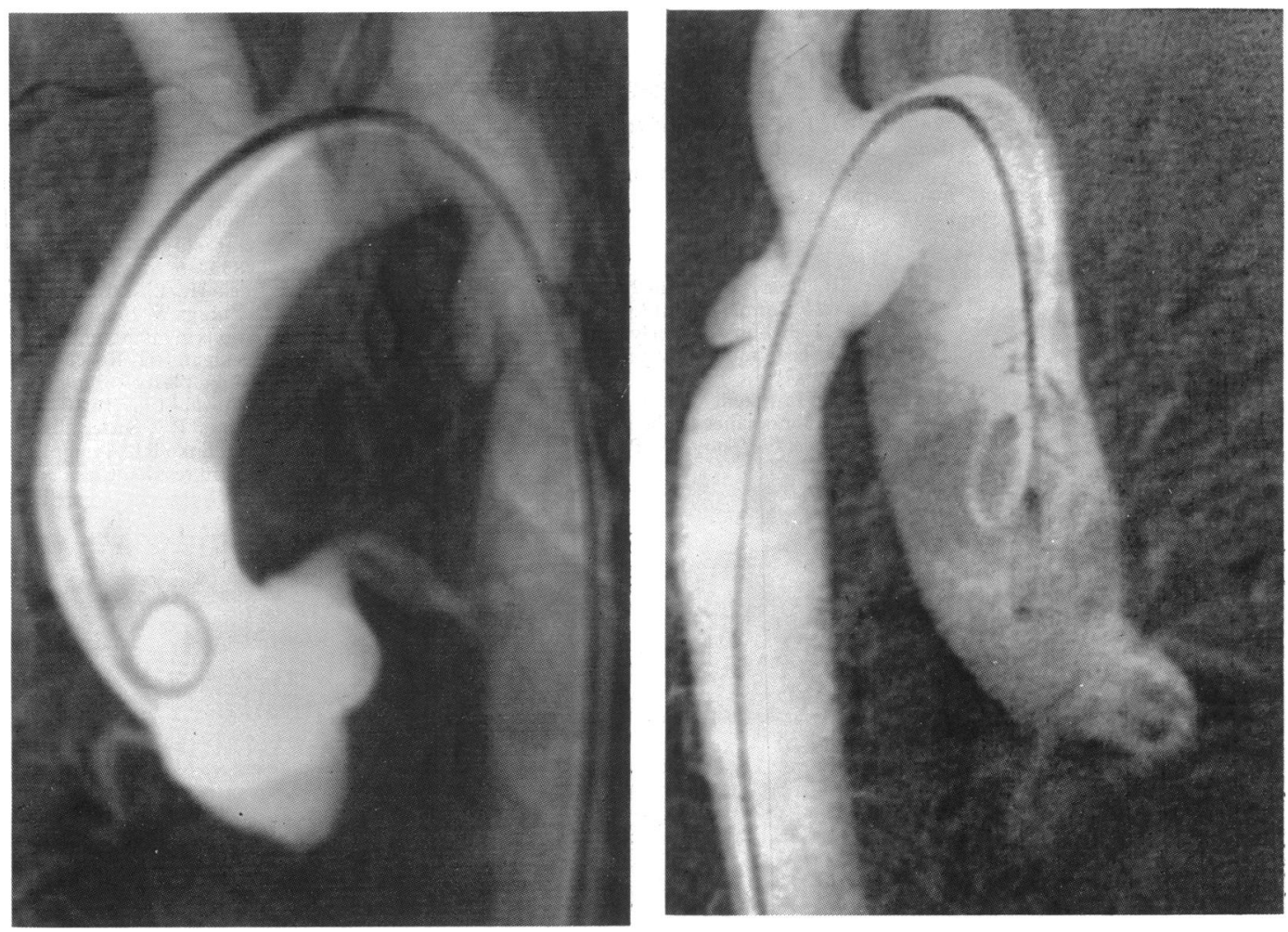

Figure 7 Angiogram at 12 month follow up showing a

with surgery. Whereas surgery is effective it is costly and necessitates a hospital stay of at least 10 days with a painful thoracotomy and subsequent scar. By contrast, angioplasty is relatively cheap and the patients can be back at work within one week of the procedure.

Surgical mortality rate in adults averages $8.6 \%$ but is higher in patients over 40 years of age. ${ }^{3}$ Major complications include paraplegia $(1 \%-2 \%),{ }^{4}$ restenosis $(1.5 \%),{ }^{5}$ and aneurysm formation when patch graft repair has been performed (33\%).

In this series, and in our search of published data, it would seem that no deaths had been

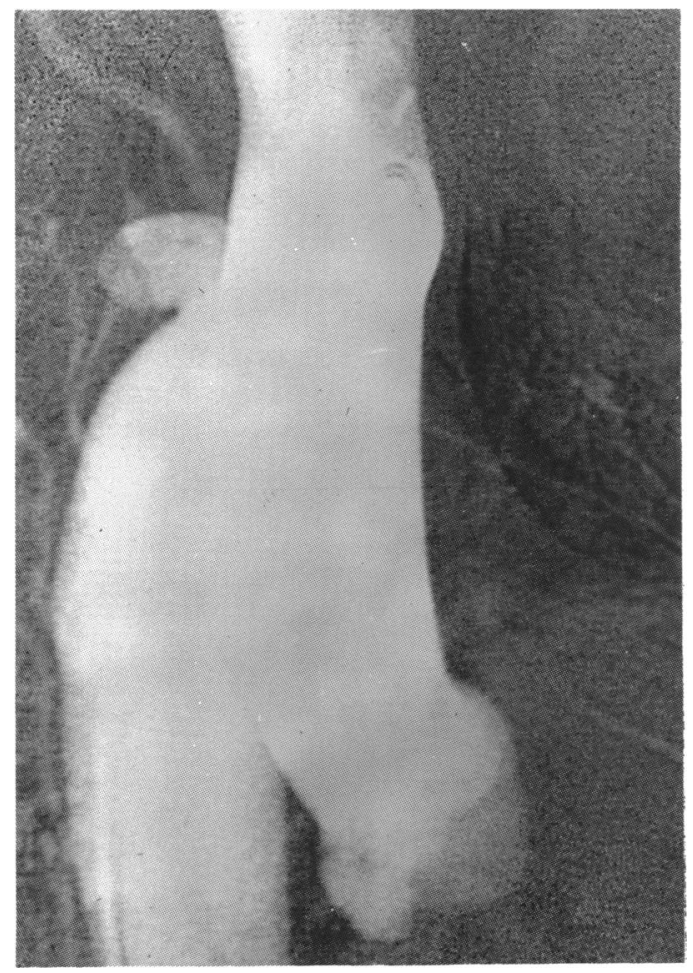

possible aneurysm posteriorly. Note that it does not bulge beyond the projected wall of the aorta-right anterior oblique projection.

reported during the procedure on native coarctation in adults. Neither restenosis nor paraplegia have been reported in adult coarctation treated by angioplasty. False aneurysm formation, however, does occur after angioplasty (variously reported from $6 \%-40 \%{ }^{1}$ ). An incidence of $15.4 \%$ in our series suggests that this appears to be the only major complication requiring surgical repair.

Whereas the experience of balloon angioplasty in adult coarctation is limited more data is available on the technique in infants and children, in whom short-term results are similar in the two groups but the long-term benefits have been less sustained in the younger age group. ${ }^{1}$ Several studies have reported a return or an increase in the pressure gradient across the coarctation starting soon after the dilatation. ${ }^{7-9}$ It is suggested that the results are better when the procedure has been performed after infancy.

In children the incidence of formation of aneurysms is similar to that in adults. ${ }^{1}$ Other complications in this paediatric group include some deaths, most of which have been related to the presence of other congenital cardiac anomalies, such as patent ductus arteriosis. ${ }^{1}$

Although the duration of follow up in our patients is short (up to 48 months), we believe that if an aneurysm is going to develop there is likely to be some evidence of this on the one year angiogram. It is our intention to continue follow up for a period of at least five years, with further intravenous digital subtraction angiography being performed at three and five years.

We conclude that angioplasty may well become the treatment of choice in uncomplicated native adult coarctation, but it may be 
that serial dilatation would lead to less formation of false aneurysms.

We thank Dr RW Portal and Dr JL Caplin for allowing their patients to be included in this series.

We also thank Miss $\mathrm{C}$ Whatling for typing and preparing the manuscript.

Ritter SB. Coarctation and balloons: inflated or realistic? $J$ Am Coll Cardiol 1989;13:696-9.

2 Attia IM, Lababidi ZA. Early results of balloon angioplasty of native coarctation in young adults. Am J Cardiol 1988; of native

3 Bahnson HT. Patent ductur arteriosus, coarctation of the aorta and anomalies of the aortic arch. In: Sabiston DC ed. Textbook of surgery. Philadelphia: W B Saunders, 1972:2213-31.
4 Clarkson PM, Nicholson MR, Barratt-Boyes BG, Nevtze JM, Whitlock RM. Results after repair of coarctation of the aorta beyond infancy. A 10 to 28 year follow-up with particular reference to late systemic hypertension. $\mathrm{Am} \mathrm{J}$ Cardiol 1981;51:1481-8.

5 Beekman RH, Ricchini AP, Behrendt DM, Rosenthal A. Reoperation for coarctation of the aorta. Am J Cardiol 1981; 48:1108-14.

6 Ala-Kulju K, Keikkinen L. Aneurysms after patch graft aortoplasty for coarctation of the aorta: long term results for surgical management. Ann Thorac Surg 1989;47: 8533-6.

7 Lock JE, Bass JC, Amplatz K. Fuhrman BP, CastanedaZuniga W. Balloon dilatation angioplasty of aortic coarctations in infants and children. Circulation 1983;68:109-16.

8 Beekman RH, Rocchini AP, Dick M. Percutaneous balloon angioplasty for native coarctation of aorta. J $\mathrm{Am}$ Coll Cardiol 1987;10:1078-84.

9 Cooper RS, Ritter SB, Rothe WA, Chen CK, Griepp R, Golinko RJ. Angioplasty for coarctation of the aorta: long term results. Circulation 1987;75:600-4. 